\title{
Immunoreactivity of MIC2 (CD99) in Acute Myelogenous Leukemia and Related Diseases
}

\author{
Paul J. Zhang, M.D., Maurice Barcos, M.D., Carleton C. Stewart, Ph.D., Annemarie W. Block, Ph.D., \\ Sheila Sait, Ph.D., John J. Brooks, M.D., FRC Path. \\ Departments of Pathology and Laboratory Medicine, University of Pennsylvania Medical Center (PJZ), \\ Philadelphia, Pennsylvania, and Roswell Park Cancer Institute (MB, CCS, AWB, SS, JJB), Buffalo, \\ New York
}

MIC2 is characteristically expressed in lymphoblastic lesions and Ewing's/primitive neuroectodermal tumor sarcomas. Although MIC2 has recently been reported in chloroma and rare terminal deoxynucleotidyl transferase-positive acute myelogenous leukemia (AML), the incidence and the significance of MIC2 (CD99) immunoreactivity in myeloid lesions is not clear. In this study, we evaluated MIC2 positivity in a variety of myeloid diseases and normal marrow to determine its incidence and distribution in myeloid diseases; its correlation with flow cytometric and cytogenetic data in AML; and its association with leukemic transformation, relapse, and chloroma formation. Paraffin sections of 11 chloromas and 94 bone marrow core biopsies from 66 patients were stained with CD99 monoclonal antibody 12E7. Of 94 bone marrow core biopsies, there were $30 \mathrm{AML}$ (fragment antigen binding M0 to M6), 23 remissions, 5 relapses, 12 myeloproliferative disorders, 13 myelodysplastic syndromes, and 11 normal marrows from patients who did not have leukemia. CD99 immunoreactivity was evaluated with light microscopy. MIC2 expression was seen in leukemic blasts in 6 of 11 chloromas (55\%) and 13 of 30 AML (43\%) but rarely in myeloproliferative disorders, myelodysplastic syndromes, remission, and normal marrow. CD99 tended to be positive in M1-, M3-, and HLA-Dr-negative AML and negative in AML with relapse. MIC2 expression did not correlate with the karyotype independent of FrenchAmerican-British Cooperative Group classification and the disease remission or occurrence of chloroma in AML. We concluded that MIC2 is commonly expressed in leukemic blasts of AML and is not pre-

Copyright (C) 2000 by The United States and Canadian Academy of Pathology, Inc.

VOL. 13, NO. 4, P. 452, 2000 Printed in the U.S.A.

Date of acceptance: August 10, 1999.

Address reprint requests to: Paul J. Zhang, M.D., Department of Pathology and Laboratory Medicine, Division of Anatomic Pathology, University of Pennsylvania Medical Center, Spruce Street/6 Founders, Philadelphia, PA 19104-4283; e-mail: pjz@mail.med.upenn.edu; fax 215-349-5910. dictive of leukemic transformation from myeloproliferative disorders and myelodysplastic syndromes or chloroma formation. Caution should be taken when using MIC2 as a marker for Ewing's sarcoma/ primitive neuroectodermal tumor or lymphoblastic lymphoma on paraffin sections of either soft tissue or bone marrow specimens.

KEY WORDS: Acute leukemia, CD99, Chloroma, Ewing's/primitive neuroectodermal tumor, Immunohistochemistry, MIC2.

Mod Pathol 2000;13(4):452-458

Transmembrane glycoprotein p30/32 ${ }^{\mathrm{mic} 2}$ (CD99) is a product of the MIC2 gene located on the pseudoautosomal region of $\mathrm{X}$ and $\mathrm{Y}$ chromosomes. The MIC2 gene is virtually expressed in all human tissues (1-6). The detection of MIC2 expression by immunohistochemistry-utilizing antibodies, such as HBA71, 12E7, and O13, on routine paraffin sections is considered diagnostically useful for Ewing's sarcoma/primitive neuroectodermal tumor (PNET) and lymphoblastic tumors, when associated with the proper histologic background and immunoprofile (6-11). As a result of the antigen retrieval technology, however, more and more tumors now are reported to overexpress MIC2 $(5,12)$. Immunohistochemical expression of MIC2 has been recently described in chloroma (granulocytic sarcoma) and rare terminal deoxynucleotidyl transferase (TdT)positive acute myelogenous leukemia (AML) (13, 14). However, MIC2 expression in a variety of myeloid disorders has not been systematically investigated, and little is known about the significance of detectable MIC2 expression in various myeloid diseases. The current study evaluated MIC2 expression in AML and its related diseases thereof in a large series to determine its incidence and distribution; its correlation with immunophenotypic and karyotypic data; and its potential for prediction of leukemic transformation, relapse, and chloroma formation. 


\section{DESIGN AND METHODS}

Eleven chloroma cases were identified in the file of surgical pathology at Roswell Park Cancer Institute from 1995 to 1998. From the same period, 94 bone marrow biopsy specimens were randomly selected. There were 30 cases of AML (M0 [n = 1], M1 $[\mathrm{n}=5]$, M2 [n = 8], M3 [n = 3], M4 [n = 3], M5 [n = 4], M6 [n = 4], chronic myelogenous leukemia in blast phase [ $\mathrm{n}=2]$ ), 12 cases of myeloproliferative disorder (MPD), 13 cases of myelodysplastic syndrome (MDS), and 11 cases of normal hematopoietic marrow from patients who did not have leukemia. In 23 of the 30 patients with AML, remission marrows (RM) were also evaluated. Five of the patients with AML developed relapse in fewer than 6 months, and their relapsed marrow biopsies were included in the study. A total of 66 patients were included in the study. Each bone marrow biopsy was placed in $15 \mathrm{~mL}$ of $\mathrm{B} 5$ fixative at the time of the procedure. At arrival in the laboratory, $1 \mathrm{~mL}$ of $37 \%$ formalin was added to each container. The specimens were fixed for 2 to $2.5 \mathrm{~h}$, then decalcified in CMS Protocol Decalcifier B (Fisher Scientific, Pittsburgh, PA) for 2.5 to $3 \mathrm{~h}$ before processing. Other specimens were fixed in $10 \%$ neutral buffered fixative for 6 to $12 \mathrm{~h}$. Paraffin sections of the above specimens were stained with monoclonal CD99 antibody 12E7, 1:200 (DAKO, Carpinteria, CA), in an automated staining system (Ventana, Tucson, AZ) with a standard avidin-biotin-peroxidase complex method. Antigen retrieval with microwave oven at $100^{\circ} \mathrm{C}$ for $10 \mathrm{~min}$ in $0.01 \mathrm{M}$ citrate buffer at $\mathrm{pH} 6.0$ was applied before incubation of the primary antibody. The primary antibody was replaced by 1:1000 normal mouse serum on an additional section of each block as a negative control.

The CD99 immunostain was evaluated with light microscopy. Immunoreactivity was recorded as follows: no reactivity (-), positivity in fewer than 10 cells $(\mathrm{R}+)$, positivity in more than 10 cells to $70 \%$ of the total cell population $(+)$. Data of the marrow flow cytometric and cytogenetic analyses performed at the time of the diagnosis in 29 patients with AML were available for correlation with MIC2 immunoreactivity.

\section{RESULTS}

Leukemic blasts expressed MIC2 gene product (CD99) as detected by monoclonal antibody 12E7 in 6 of 11 chloromas (55\%) and 13 of 30 cases of AML (43\%) on paraffin sections (Tables 1-3; Figs. 1 and 2). The CD99 immunoreactivity was characteristically membranous with light cytoplastic staining in some instances. Significant CD99 reactivity was also observed in 1 of 12 cases of MPD (8\%) and 1 of 13 cases of MDS (8\%) (Tables 1 and 4). The only CD99-positive MPD was a case of polycythemia vera in blast phase, and the only CD99-positive MDS subsequently developed AML. However, three other CD99-negative MDS cases also developed AML. Rare MIC2-positive cells are seen in a few samples of normal blood marrow (Tables 1 and 4; Fig. 3A). The morphology of MIC2positive cells in the nonleukemic marrows seemed to be primitive myeloid precursors, though definitive lineage and the stage of early maturation of the cells cannot be fully determined on paraffin-immunostained sections. MIC2 immunoreactivity was also detected in reactive lymphoid aggregates, but there was no MIC2 immunoreactivity seen in mature myeloid cells, normal erythroid lineage, and megakaryocytes.

The MIC2 expression was not strictly limited to specific leukemic types in the modified FrenchAmerican-British Cooperative Group classification. It was detected most commonly in leukemic marrow of M1 (4 of $5[80 \%]$ ) and M3 cases (3 of 3 [100\%]) (Fig. 1), less commonly in M2 (3 of 8 [37.5\%]) and M4 cases (1 of 3 [33\%]), and rarely in M5 and M6 cases (1 of 8 [13\%]) (Tables 2 and 5). Two of four originally CD99-negative M5 patients developed CD99-positive relapse or chloroma, respectively. The only M0 patient developed chloroma; CD99 was negative in the marrow but positive in the chloroma (Table 3 ).

Seven of $23 \mathrm{RM}(30 \%)$ contained rare $(<10, \mathrm{R}+)$ CD99-positive cells (Fig. 3B). Similar to the leukemic phase, the rare CD99-positive cells were more commonly seen in RM of M1 (3 of 4) and M3 (2 of 3 ), less commonly in M2 ( 1 of 4 ) and M4 (1 of 3), but not in any M5 or M6 cases. The rare cases of CD99 positivity $(\mathrm{R}+)$ were seen in RM of either CD99positive (4 of 7) or CD99-negative (3 of 7) AML (Table 2). Four of 16 patients with CD99-negative

TABLE 1. Summary of CD99 Immunoreactivity

\begin{tabular}{|c|c|c|c|c|c|c|c|}
\hline CD99 & $\begin{array}{l}\text { Chloroma } \\
(n=11)\end{array}$ & $\begin{array}{c}\text { AML } \\
(n=30)\end{array}$ & $\begin{array}{c}\mathrm{RM} \\
(n=23)\end{array}$ & $\begin{array}{l}\text { Relapse } \\
(n=5)\end{array}$ & $\begin{array}{c}\text { MPD } \\
(n=12)\end{array}$ & $\begin{array}{c}\text { MDS } \\
(n=13)\end{array}$ & $\begin{array}{l}\text { Normal marrow } \\
\quad(n=11)\end{array}$ \\
\hline+ & $6(55 \%)$ & $13(43 \%)$ & 0 & $1(20 \%)$ & $1^{a}(8 \%)$ & $1^{b}(8 \%)$ & 0 \\
\hline $\mathrm{R}+$ & 0 & $2(6 \%)$ & 7 (30\%) & 0 & 0 & $2 \quad(15 \%)$ & $5(45 \%)$ \\
\hline
\end{tabular}

AML, acute myelogenous leukemia; RM, remission marrow; MPD, myeloproliferative disorder; MDS, myelodysplastic syndrome; +, positivity in more than 10 cells to $70 \%$ of the total cell population; $\mathrm{R}+$, positivity in fewer than 10 cells.

${ }^{a}$ In blast phase.

${ }^{b}$ Subsequently developed AML. 
TABLE 2. CD99 Reactivity and Karyotype in AML without Chloroma

\begin{tabular}{|c|c|c|c|c|c|c|c|}
\hline \multirow{2}{*}{ Patient } & \multirow{2}{*}{ FAB } & \multicolumn{5}{|c|}{ CD99 Immunoreactivity } & \multirow{2}{*}{ Cytogenetics } \\
\hline & & AML BM & RM & Relapse & Pre-AML MDS & Pre-AML CMML & \\
\hline 1 & M1 & + & NA & & & & 46, XX \\
\hline 2 & M1 & + & - & & & & 46, XY \\
\hline 3 & M1 & - & $\mathrm{R}+$ & & & & 46, XY, del(5)(q12;q33), del7(q22;q32) \\
\hline 4 & M1 & + & $\mathrm{R}+$ & & & & $46, \mathrm{XY}$ \\
\hline 5 & M1 & + & $\mathrm{R}+$ & & & & $46, \mathrm{XY}$ \\
\hline 6 & M2 & + & NA & & + & & $45, \mathrm{XX}, \operatorname{add}(5)(\mathrm{q} 31),-16, \operatorname{del}(12)(\mathrm{p} 12), \operatorname{inv}(17)$ \\
\hline 7 & M2 & - & - & & & & NA \\
\hline 8 & M2 & + & NA & & & - & 46, XX \\
\hline 9 & M2 & $\mathrm{R}+$ & - & & - & & $46, \mathrm{XX}$ \\
\hline 10 & M2 & + & NA & & & & 46, XY \\
\hline 11 & M2 & - & $\mathrm{R}+$ & & & & 47, X-Y,+8, del(9), +21 t(8;21)(q22;q22) \\
\hline 12 & M2 & - & - & - & & & $46, \mathrm{XY}$ \\
\hline 13 & M2 & - & NA & & & - & NA \\
\hline 14 & M3 & + & $\mathrm{R}+$ & & & & 46, XY, t(15;17)(q22;q11) \\
\hline 15 & M3 & + & - & & & & $46, \mathrm{XX}, \mathrm{t}(15 ; 17)(\mathrm{q} 22 ; \mathrm{q} 11-12)$ \\
\hline 16 & M4 & - & $\mathrm{R}+$ & & & & $47, \mathrm{XY},+8$ \\
\hline 17 & M4 & - & - & - & & & 46, XY \\
\hline 18 & M5 & - & - & & & & NA \\
\hline 19 & M5 & - & - & & & & $46, \mathrm{XY}$ \\
\hline 20 & M5 & - & - & + & & & 46, XX \\
\hline 21 & M6 & - & - & - & & & 44-46, XY, del5(q13;q35), inv(7) \\
\hline 22 & M6 & - & - & & & & $43-45, \mathrm{XY},-3, \operatorname{del}(5) \operatorname{del}(9),-17, \operatorname{add}(19)+\operatorname{mar},+\min$ \\
\hline 23 & M6 & - & - & - & & & NA \\
\hline 24 & M6 & + & NA & & & & 46, XY \\
\hline
\end{tabular}

AML, acute myelogenous leukemia; FAB, modified French-American-British Cooperative Group classification; BM, bone marrow; RM, remission marrow; MDS, myelodysplastic syndrome; CMML, chronic myelomonocytic leukemia; +, positivity in more than 10 cells to $70 \%$ of the total cell population; -, no reactivity; $\mathrm{R}+$, positivity in fewer than 10 cells; NA, not available.

TABLE 3. CD99 Reactivity and Karyotype in Chloroma Cases

\begin{tabular}{|c|c|c|c|c|c|c|}
\hline \multirow{2}{*}{ Patient } & \multirow{2}{*}{ Site } & \multirow{2}{*}{ BM Diagnosis } & \multicolumn{3}{|c|}{ CD99 } & \multirow{2}{*}{ Cytogenetics } \\
\hline & & & Chloroma & AML BM & $\mathrm{RM}$ & \\
\hline 1 & Forearm skin & AML, M4 & - & + & - & $46, \mathrm{XY}$ \\
\hline 2 & Neck lymph node & AML & + & NA & NA & NA \\
\hline 3 & Perianal area & AML, M3 & - & + & $\mathrm{R}+$ & $46, \mathrm{XY}, \mathrm{t}(15 ; 17)(\mathrm{q} 22 ; \mathrm{q} 11-12)$ \\
\hline 4 & Scalp & AML, Mo & + & $\mathrm{R}+$ & - & 46, XY \\
\hline 5 & Chest skin & MDS & - & - & - & $46, \mathrm{XY}$ \\
\hline 6 & Periumbilical area & CML blast phase & + & + & - & $47, \mathrm{XY},+8, \mathrm{t}(9 ; 22)(\mathrm{q} 34 ; \mathrm{q} 11), \mathrm{t}(15 ; 21)(\mathrm{q} 22 ; \mathrm{q} 22)$ \\
\hline 7 & Right clavicle skin & CML to AML & + & - & NA & $46, X Y, \operatorname{inv}(11)(q 21 ; q 24)$ \\
\hline 8 & Upper back skin & AML, M5a & + & Lymphoid+ & - & 46, XY \\
\hline 9 & $?$ & AML, M5b & - & NA & NA & $46, \mathrm{XY}$ \\
\hline 10 & Right temporal skin & Not done & - & NA & NA & $46, \mathrm{XY}$ \\
\hline 11 & Pericervical spine & Nonleukemic & + & NA & NA & NA \\
\hline
\end{tabular}

BM, bone marrow; AML, acute myelogenous leukemia; RM, remission marrow; MDS, myelodysplastic syndrome; CML, chronic myelogenous leukemia; NA, not available.

RM originally had CD99-positive AML. Four of the five patients with AML who experienced a relapse in 6 months were CD99 negative, and the fifth was CD99 positive in the relapse marrow only (Table 1).

Of the seven patients with chloroma and whose AML marrow samples were tested, MIC2 immunoreactivity was positive in leukemic marrow and negative in chloroma in two, positive in chloroma and negative in marrow in two, negative in both marrow and chloroma in one, positive in both marrow and chloroma in one, and rarely positive $(\mathrm{R}+)$ in marrow and positive in chloroma in one (Table 3 ). One of the chloromas developed in a patient who did not have leukemia and was CD99 positive; this patient had originally been diagnosed with Ewing's/PNET sarcoma attributed to MIC2 reactivity (Fig. 2; Table 3).
HLA-Dr was positive in only 3 of 12 cases $(25 \%)$ of CD99-positive AML but in 10 of 14 cases (71\%) of CD99-negative AML. Otherwise, there was no correlation between CD99 and expression of any specific myeloid surface markers in AML, as determined by flow cytometry (Table 5). MIC2 expression was associated with all three cases of M3 AML with $\mathrm{t}(15 ; 17)(\mathrm{q} 22 ; \mathrm{q} 11)$ translocation but did not show a correlation with any specific abnormal karyotypes independent of FAB classification, as determined by cytogenetics (Tables 2 and 3 ).

\section{DISCUSSION}

In soft tissue tumors, MIC2 expression has long been used as a diagnostic marker for Ewing's/PNET 

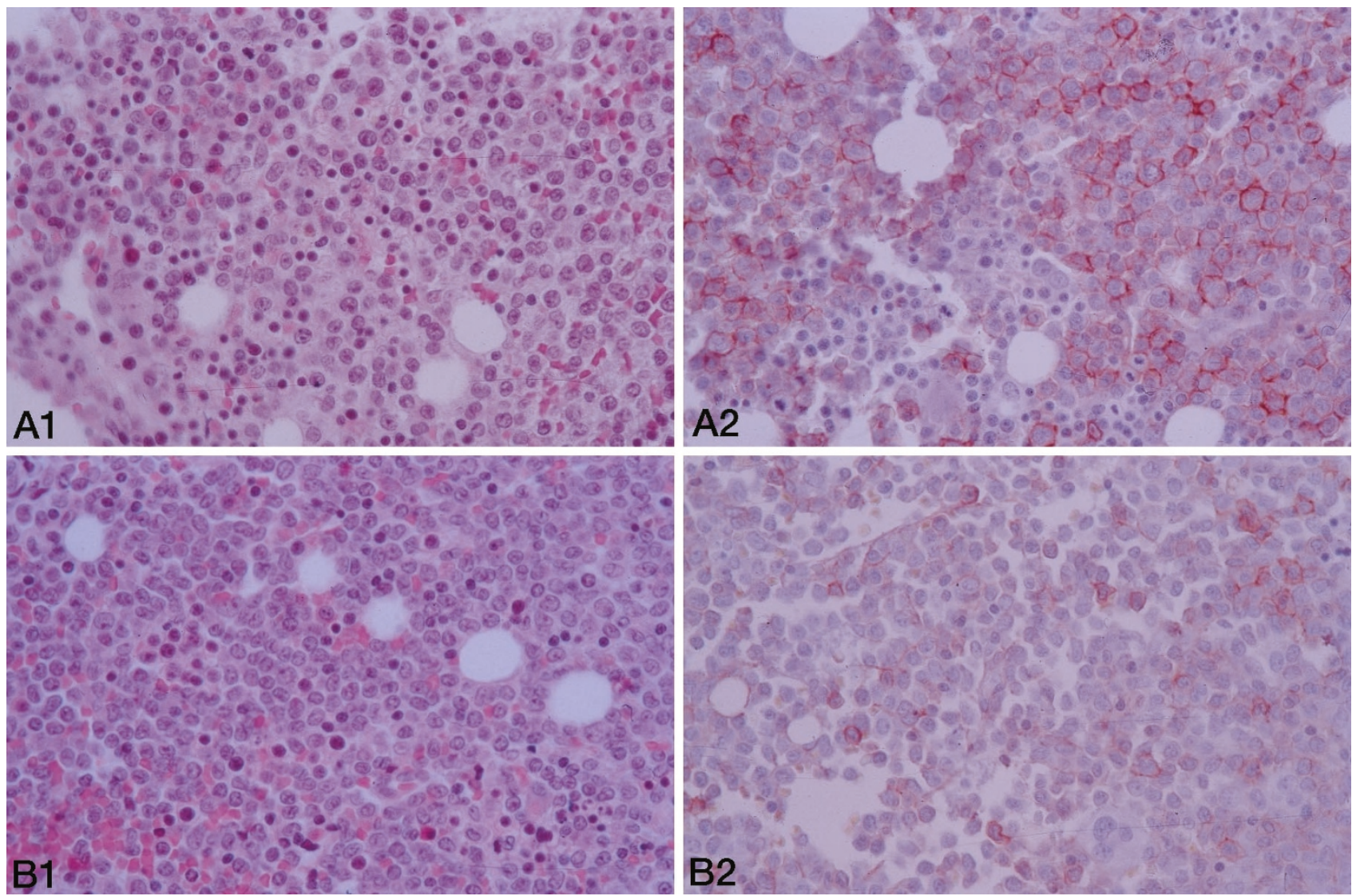

FIGURE 1. Membranous MIC2 immunoreactivity in leukemic blasts of an M3 (A) and M1 AML (B).
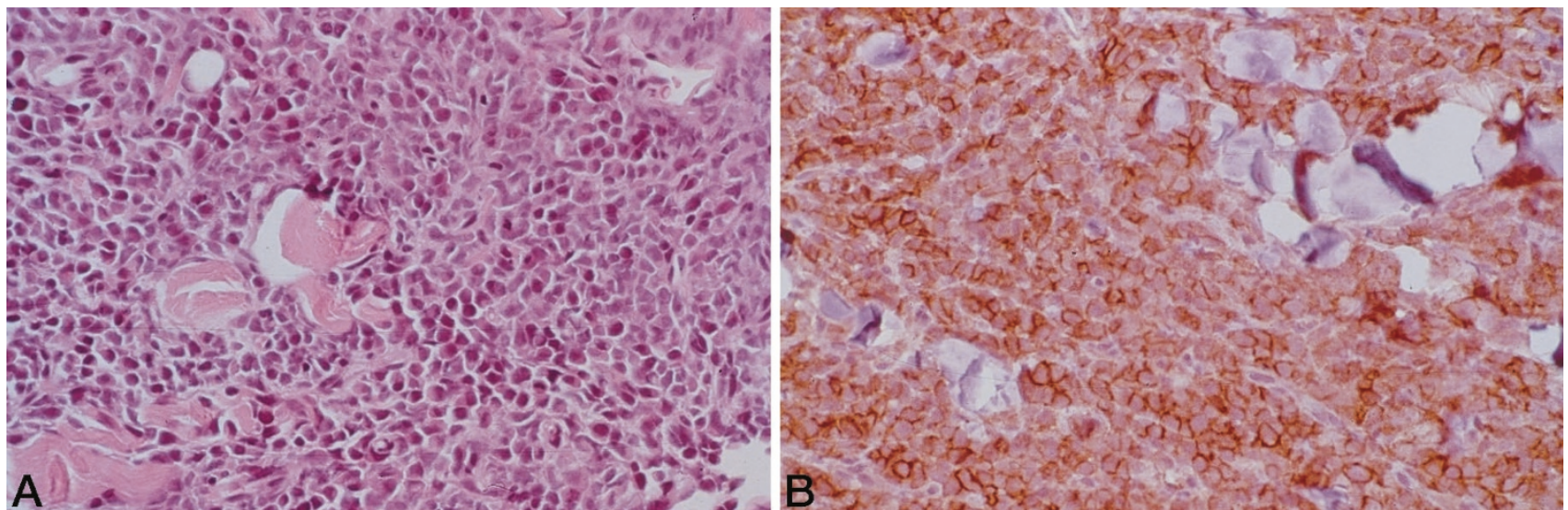

FIGURE 2. Chloroma of the paracervical spine soft tissue, with MIC2 immunoreactivity (Patient 11, Table 3).

sarcomas, although recently, more and more tumors have been added to the list of tumors with MIC2 immunoreactivity (5-9, 12). In hematopoietic diseases, MIC2 expression had also been considered a marker for the lymphoblast and its diseases $(1,10,11)$. Previously, in myeloid diseases, there was only one study describing MIC2 in rare TdTpositive AML (14) and another involving MIC2positive chloromas (13). Knowledge of MIC2 reactivity in chloromas and leukemic infiltrates has important clinical and diagnostic implications, as such tumors may be mistaken for small round cell sarcomas, such as Ewing's/PNET sarcoma (as occurred in one of our patients).

In this study, we systematically tested virtually all types of myeloproliferative diseases to evaluate better the distributions of MIC2 (CD99) reactivity. Using the decalcified B5 fixed bone marrow specimens, we were able to identify CD99 immunoreactivity in leukemic blasts in $43 \%$ of patients with AML. MIC2 expression does not seem to be restricted to certain leukemias in the FAB classification, but it tends to occur in acute nonlymphoid leukemias with differentiation toward myeloid lineages such as M1 to M4 AML, with the 
TABLE 4. CD99 in Other Myeloid Disorders and NBM

\begin{tabular}{|c|c|c|}
\hline No. & Diagnosis & CD99 \\
\hline \multicolumn{3}{|l|}{ MPD } \\
\hline 1 & Polycythemia vera (blast phase) ${ }^{a}$ & + \\
\hline 2 & Polycythemia vera & - \\
\hline 3 & MPD & - \\
\hline 4 & MPD/chronic myelogenous leukemia & - \\
\hline 5 & MPD (blast phase) & - \\
\hline 6 & Myelofibrosis with increased blasts & - \\
\hline 7 & Chronic MPD & - \\
\hline 8 & CML & - \\
\hline 9 & CML & - \\
\hline 10 & CML & - \\
\hline 11 & CML with increased blasts & - \\
\hline 12 & CML with increased blasts & - \\
\hline \multicolumn{3}{|l|}{ MDS } \\
\hline 1 & Chronic myelomonocytic leukemia & - \\
\hline 2 & Chronic myelomonocytic leukemia ${ }^{a}$ & - \\
\hline 3 & Chronic myelomonocytic leukemia ${ }^{a}$ & - \\
\hline 4 & Pre-AML MDS ${ }^{a}$ & + \\
\hline 5 & Pre-AML MDS ${ }^{a}$ & - \\
\hline 6 & Refractory anemia & - \\
\hline 7 & Refractory anemia & - \\
\hline 8 & Refractory anemia & - \\
\hline 9 & Refractory anemia with excess of blasts & $\mathrm{R}+$ \\
\hline 10 & Refractory anemia with excess of blasts & $\mathrm{R}+$ \\
\hline 11 & Refractory anemia with excess of blasts & - \\
\hline 12 & Refractory anemia with excess of blasts & - \\
\hline 13 & Refractory anemia with ring sideroblasts & - \\
\hline \multicolumn{3}{|c|}{ 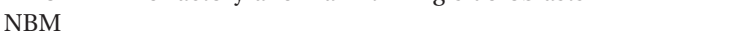 } \\
\hline 1 & Cervical intraepithelial neoplasm & $\mathrm{R}+$ \\
\hline 2 & Hodgkin disease & - \\
\hline 3 & Hodgkin disease & $\mathrm{R}+$ \\
\hline 4 & Non-Hodgkin lymphoma & $\mathrm{R}+$ \\
\hline 5 & Hodgkin disease & - \\
\hline 6 & Non-Hodgkin lymphoma & - \\
\hline 7 & Breast carcinoma & - \\
\hline 8 & Breast carcinoma & $\mathrm{R}+$ \\
\hline 9 & Non-Hodgkin lymphoma & - \\
\hline 10 & Non-Hodgkin lymphoma & $\mathrm{R}+$ \\
\hline 11 & Non-Hodgkin lymphoma & - \\
\hline
\end{tabular}

${ }^{a}$ Developed AML subsequently.

MPD, myeloproliferative disorder; MDS, myelodysplastic syndrome; NBM, normal bone marrow; CML, chronic myelogenous leukemia; AML, acute myelogenous leukemia.

highest incidence in M1 and M3 (80\% and 100\%) and the lowest incidence in M5 and M6 (13\%). Immunophenotypically, CD99 positivity seems to be more commonly detected in HLA-Dr-negative AML (67\%) than in HLA-Dr-positive AML (23\%). The significance of this inverse association is not clear. Although all three cases of M3 AML with $\mathrm{t}(15 ; 17)(\mathrm{q} 22 ; \mathrm{q} 11)$ were CD99 positive, MIC2 expression does not correlate with any specific karyotypes independent of FAB classification. CD99 reactivity does not correlate with leukemic remission or development of chloroma in patients with AML. With limited numbers of relapsed AML tested, CD99 tended to be negative in those that relapsed in fewer than 6 months. Larger series of relapsed AML with proper follow-up and controls are necessary to evaluate further the significance of MIC2 expression in AML relapse.

TdT initially was considered a marker of immature lymphoid cells, and a high level of TdT is characteristically found in acute lymphoblastic leukemia or lymphoma (15). Subsequently, some cases of AML were also found to be TdT positive. The incidence of TdT positivity in AML varies greatly in different studies, with an average of $18 \%$ of AML cases being TdT positive (16). The level of TdT expression in TdT-positive AML is usually low. In some studies, it is more common in M0 to M2; in other studies, it is more common in M4 and M5 (16-19). CD99 has been shown to correlate with TdT positivity in acute lymphoblastic leukemia (14). In the same series, one TdT-positive AML was also found to be CD99 positive. Because of the relatively high incidence of CD99 reactivity in AML and chloroma, particularly in M3 AML in our series, one can speculate that MIC2 expression is probably not limited to TdT-positive AML.

In contrast to AML, incidence of CD99 immunoreactivity was significantly lower in MPD and MDS $(8 \%)$ and did not predict leukemic transformation in these diseases. Rare CD99-positive blasts (fewer than 10 cells) are found in $30 \%$ of the remission marrows and $45 \%$ of the normal hematopoietic marrows from patients who did not have leukemia, in which blast counts are normally low. Rare CD99positive blasts $(\mathrm{R}+)$ also tend to develop in the remission marrows of $\mathrm{M} 1$ and $\mathrm{M} 3$ patients, but this
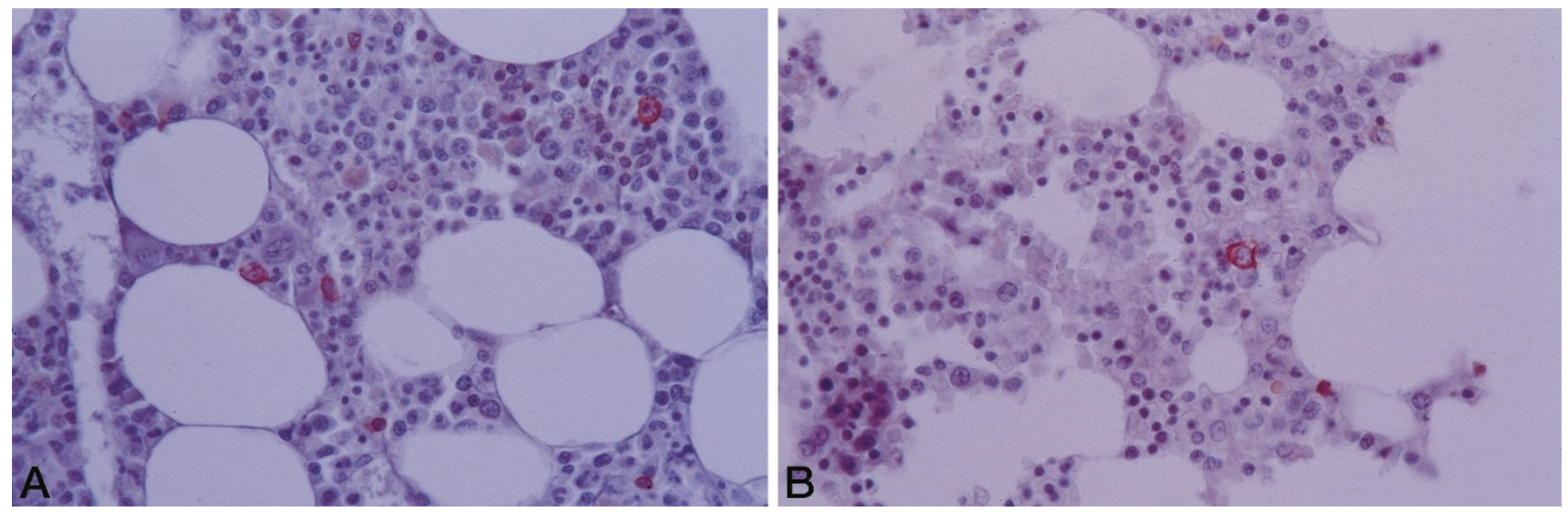

FIGURE 3. Rare MIC2-positive cells in a normal marrow (A) and the remission marrow of the M1 AML shown on Figure 1B (B). 


\begin{tabular}{|c|c|c|c|c|c|c|c|c|c|c|c|c|c|c|c|c|c|c|}
\hline & CD2 & $\mathrm{CD} 4$ & CD7 & CD11b & CD11c & CD13 & $\mathrm{CD} 14$ & CD15 & CD16 & CD19 & CD32 & CD33 & CD34 & CD38 & CD45 & CD56 & CD64 & HLADr \\
\hline \multicolumn{19}{|l|}{ CD99+ } \\
\hline M1 & & & & & $\mathrm{h}$ & + & & & & & & $\mathrm{h}$ & + & & $\mathrm{d}$ & & & \\
\hline M1 & & $\mathrm{h}$ & & $\mathrm{h}$ & + & $\mathrm{h}$ & & & & & $\mathrm{h}$ & + & & + & + & & & \\
\hline M1 & & & + & & $\mathrm{h}$ & + & & + & & & + & + & + & + & $\mathrm{d}$ & & & + \\
\hline M1 & & & & & $\mathrm{h}$ & $\mathrm{h}$ & & $\mathrm{h}$ & & & & $\mathrm{h}$ & + & + & + & & & + \\
\hline M2 & & + & & + & + & & $\mathrm{h}$ & + & & & + & + & $\mathrm{h}$ & + & + & & $\mathrm{h}$ & + \\
\hline M2 & & $\mathrm{h}$ & & + & & $\mathrm{h}$ & $\mathrm{h}$ & $\mathrm{h}$ & $\mathrm{s}$ & & $\mathrm{h}$ & + & & & + & & $\mathrm{h}$ & $\mathrm{h}$ \\
\hline M2 & & + & & + & + & + & + & + & + & & + & + & $\mathrm{h}$ & & + & & + & $\mathrm{h}$ \\
\hline M3 & & $\mathrm{h}$ & & & & + & & & & & + & + & $\mathrm{h}$ & & $\mathrm{d}$ & & $\mathrm{h}$ & \\
\hline M3 & & & & & & + & & & & & $\mathrm{h}$ & + & & & $\mathrm{d}$ & & $\mathrm{h}$ & \\
\hline M3\# & & & & & & + & & & & & & + & & + & + & & & \\
\hline M4\# & & + & & $\mathrm{h}$ & $\mathrm{h}$ & + & & & & & & + & + & + & + & & + & \\
\hline M6 & & + & + & $\mathrm{h}$ & + & + & & & & & & + & + & $\mathrm{h}$ & + & & & \\
\hline$\%$ & 0 & $33 \%$ & $17 \%$ & $25 \%$ & $33 \%$ & $66 \%$ & $8 \%$ & $25 \%$ & $8 \%$ & 0 & $33 \%$ & $83 \%$ & $42 \%$ & $50 \%$ & $66 \%$ & 0 & $17 \%$ & $25 \%$ \\
\hline \multicolumn{19}{|l|}{ CD99- } \\
\hline M0\# & & & & & & + & & & & & & & + & $\mathrm{h}$ & $\mathrm{d}$ & & & + \\
\hline M1 & & & & & & + & & & & & + & & + & & $\mathrm{d}$ & & & + \\
\hline M2 & & + & $\mathrm{h}$ & $\mathrm{h}$ & & + & & & & & & + & + & + & $\mathrm{d}$ & & & $\mathrm{h}$ \\
\hline M2 & & & & & + & $\mathrm{h}$ & & $\mathrm{s}$ & & + & + & $\mathrm{h}$ & + & + & $\mathrm{d}$ & & & + \\
\hline M2 & $\mathrm{s}$ & $\mathrm{h}$ & $\mathrm{s}$ & $\mathrm{s}$ & & + & & + & $\mathrm{s}$ & & + & + & + & + & + & & $\mathrm{s}$ & + \\
\hline M2 & & & & $\mathrm{s}$ & & $\mathrm{h}$ & & $\mathrm{s}$ & & & $\mathrm{s}$ & $\mathrm{h}$ & & & $\mathrm{d}$ & & $\mathrm{s}$ & \\
\hline M2 & & & & & & + & & & & & & & + & + & $\mathrm{d}$ & & & + \\
\hline M4 & & + & & + & + & + & $\mathrm{h}$ & + & & & & + & & + & $\mathrm{d}$ & + & & + \\
\hline M4 & & + & & & + & & $\mathrm{h}$ & + & & & $\mathrm{h}$ & + & & + & + & & $\mathrm{h}$ & + \\
\hline M5 & & + & & + & + & + & $\mathrm{h}$ & + & + & & + & + & & + & + & $\mathrm{h}$ & + & + \\
\hline M5 & & + & & + & + & + & & + & & & + & + & & & + & + & + & + \\
\hline M5 & + & + & & + & & + & & + & $\mathrm{h}$ & & + & + & & & $\mathrm{d}$ & $\mathrm{h}$ & $\mathrm{h}$ & $\mathrm{h}$ \\
\hline M5\# & & & & & & & & & & + & & & & & + & & + & \\
\hline M6 & & + & & & & + & & $\mathrm{h}$ & & & & + & + & + & + & & & + \\
\hline$\%$ & $7 \%$ & $50 \%$ & 0 & $29 \%$ & $36 \%$ & $71 \%$ & 0 & $43 \%$ & $7 \%$ & $14 \%$ & $43 \%$ & $57 \%$ & $50 \%$ & $57 \%$ & $43 \%$ & $14 \%$ & $21 \%$ & $71 \%$ \\
\hline
\end{tabular}

s, positive subset; h, heterogeneous expression; d, dim fluorescence; \#, patient developed chloroma.

does not correlate with CD99 positivity in the corresponding leukemic phase. The rare CD99-positive cells also did not predict impending relapse; rather, the remission marrows of all five cases of AML relapse were CD99 negative.

Chloroma or granulocytic sarcoma can develop in a patient who does or does not have leukemia as a soft tissue mass, raising the differential diagnosis of round cell sarcomas $(20,21)$. MIC2 expression has been frequently used as a marker, differentiating Ewing's/PNET sarcomas or lymphoblastic neoplasia from other round cell tumors (7-11). However, because of the high incidence of detectable MIC2 expression in myeloid hematopoietic neoplasms, the use of CD99 immunoreactivity is of limited value in the differential diagnosis of round cell sarcomas versus lymphoblastic lesions versus chloroma, particularly in patients who do not have leukemia. Instead, the possibility of myeloid neoplasms, including chloroma, should be considered routinely with the known MIC2 (CD99)-positive round cell tumors, such as Ewing's/PNET sarcomas, lymphoblastic lesions, and others (13).

In summary, MIC2 immunoexpression can be detected in nonlymphoid leukemic and nonleukemic blasts. MIC2 is more commonly expressed in M1-, M3-, or HLA-Dr-negative AML. There is no significant correlation of CD99 immunoreactivity with karyotype, independent of FAB classification, leukemic transformation from MPD and MDS, leu- kemic remission, or chloroma formation in AML. The significance of MIC2 negativity in AML relapse warrants further investigation. Because of the relatively high incidence of CD99 immunoreactivity, myeloid neoplasms, including chloroma, should be considered as one of the differential diagnoses in a MIC2 (CD99)-positive round cell tumor, regardless of the presence or absence of a leukemic phase and the known anatomic site of the tumor.

\section{REFERENCES}

1. Levy R, Dilley J, Fox RI, Wanke R. A human thymus leukemia antigen defined by hybridoma monoclonal antibodies. Proc Natl Acad Sci U S A 1979;76:6552-6.

2. Fellinger EJ, Garin-Chesa P, Su SL, DeAngelis P, Lane JM, Rettig WJ. Biochemical and genetic characterization of the HBA 71 Ewing's sarcoma cell surface antigen. Cancer Res 1991;51:336-40.

3. Hamilton G, Fellinger EJ, Schratter I, Fritsch A. Characterization of a human endocrine tissue and tissue-associated Ewing's sarcoma antigen. Cancer Res 1988;48:6127-34.

4. Genlin C, Aubrit F, Phalipon A, Raynal B, Cole S, Kaczorek M, et al. The E2 antigen, 32kDa glycoprotein involved in T-cell adhesion processes, is the Mic2 gene product. EMBO J 1989; 8:3253-9.

5. Stevenson AJ, Chatten J, Bertoni F, Miettinen M. CD99 (p30/32 MIC2) neuroectodermal/Ewing's sarcoma antigen as an immunohistochemical marker: review of more than 600 tumors and the literature experience. Appl Immunohistochem 1994;2:231-40.

6. Weidner N, Tjoe J. Immunohistochemical profile of monoclonal antibody O13: antibody that recognizes glycoprotein 
p30/32MIC2 and is useful in diagnosing Ewing's sarcoma and peripheral neuroepithelioma. Am J Surg Pathol 1994;18: 486-94

7. Fellinger EJ, Garin-Chesa P, Glasser DB, Huvos AG, Rettig W. Comparison of cell surface antigen HBA71 (p3/32MIC2), neuron-specific enolase and vimentin in the immunohistochemical analysis of Ewing's sarcoma of bone. Am J Surg Pathol 1992;16:746-55.

8. Perlman EJ, Dickman PS, Askin FB, Grier HE, Miser JS, Link MP. Ewing's sarcoma-routine diagnostic utilization of MIC2 analysis: a pediatric oncology group/children's cancer group intergroup study. Hum Pathol 1994;25:304-7.

9. Ramani P, Rampling D, Link M. Immunocytochemical study of 12E7 in small round-cell tumours of childhood: an assessment of its sensitivity and specificity. Histopathology 1993; 23:557-61.

10. Riopel M, Dickman PS, Link MP, Perlman EJ. MIC2 analysis in pediatric lymphomas and leukemias. Hum Pathol 1994; 25:396-9.

11. Soslow RA, Bhargava V, Wernke RA. MIC2, TdT, and CD34 expression in paraffin-embedded high-grade lymphoma/ acute lymphoblastic leukemia distinguishes between distinct clinicopathologic entities. Hum Pathol 1997;28:115865.

12. Renshaw AA. O13 (CD99) in spindle cell tumors: reactivity with hemangiopericytoma, solitary fibrous tumor, synovial sarcoma, and meningioma but rarely with sarcomatoid mesothelioma. Appl Immunohistochem 1995;3:250-6.

13. Robertson PB, Neiman RS, Worapongpaiboon S, John K,
Orazi A. O13 (CD99) positivity in hematologic proliferations correlates with TdT positivity. Mod Pathol 1997;10:227-82.

14. Cooper K, Haffajee Z. Immunohistochemical assessment of MIC2 gene product in granulocytic sarcoma using six epitope retrieval system. Appl Immunohistochem 1995;3: 198-201.

15. Drexler HG, Menon M, Minowada J. Incidence of TdT positivity in cases of leukemia and lymphoma. Acta Haematol 1986;75:12-7.

16. Drexler HG, Sperling C, Ludwig WD. Terminal deoxynucleotidyl transferase (TdT) expression in acute myeloid leukemia. Leukemia 1993;7:1142-50.

17. Lo Coco F, Lopez M, Pasqualettis D, Montefusco E, Cafolla A, Monarca B, et al. Terminal transferase positive acute myeloid leukemia: immunophenotypic characterization and response to induction therapy. Hematol Oncol 1989;7:167-74.

18. Parreira A, Pombo de Oliveira MS, Matutes E, Foroni R, Morilla L. Terminal deoxynucleotidyl transferase positive acute myeloid leukaemia: an association with immature myeloblastic leukaemia. Br J Haematol 1988;69:219-24.

19. San Miguel JF, Gonzalez M, Canizo MC, Anta JP, Portero JA, Lopez-Borrasca A. TdT activity in acute myeloid leukemia defined by monoclonal antibodies. Am J Hematol 1986;23: 9-17.

20. Miller LP, Steinherz PG, Miller DR. Granulocytic sarcoma of the clavicle. Am J Ped Hematol Oncol 1982;4:425-7.

21. Meis JM, Butler JJ, Osborne BM, Manning JT. Granulocytic sarcoma in nonleukemic patients. Cancer 1986;58:2697709 . 